\title{
SEDIMENT IMPACT ON TURBINE MATERIAL: CASE STUDY OF MODI RIVER, NEPAL
}

\author{
${ }^{1}$ L. Poudel*, ${ }^{1}$ B.Thapa, ${ }^{1}$ B.P. Shrestha, ${ }^{2}$ N.K. Shrestha \\ ${ }^{1}$ Dept. of Mechanical Engineering, Kathmandu University, Nepal \\ ${ }^{2}$ Researcher, Review Resource Nepal, Consulting firm, Kathmandu, Nepal. \\ *Corresponding address: p12_laxman@yahoo.com \\ Received 29 December, 2011; Revised 09 February, 2012
}

\begin{abstract}
Hydropower is considered as one of the most economical and stable base energy source compared with other sources of energy of Nepal. Researches coherent to this field are not new but yet it is not sufficient, lots of tiles have to be kept for better understanding of hydropower effecting elements. Sand is the most affecting element that damages the turbine blades, so research on relation of sand and turbine is most. This research is done to find out the impact of sediment on turbine material. Modi River sediment at eight different stations has been taken as sample and its erosion rate in turbine blade sample specimen has been accounted in this study. Rotating disc apparatus has been utilized to find out the total impact of sand on turbine material. Four same kind of test turbine material is used on single rotating disc all at a time at same condition to define sand impact. Thirty gram ( $\mathrm{gm}$ ) of sediment mixed with three liters of water is used to strike sample pieces for five minutes. Two different tests of sediment samples of 8 different locations were studied. After all the test it is observed that the first test sand sample of location 1 and turbine material 1 has the highest impact with a weight loss of $7.764 \mathrm{mg}$ and least impact in sand sample location 1 and sand sample 3 with a weight loss of $3.5 \mathrm{mg}$. Average weight loss of turbine material in first location is $5.929 \mathrm{mg}$ which is the greatest impact and 4.0083 at eight locations which is the least. Relating to turbine material first rotating disc turbine specimen P0A has been affected highly with weight loss of $9.289 \mathrm{mg}$ and less eroded on P5A rotating turbine specimen with weight loss of $1.2 \mathrm{mg}$.
\end{abstract}

Keywords: Rotating Disc, Sand, Turbine, Mineral Content.

\section{INTRODUCTION}

Sediment directly degrades hydraulic machines especially turbine blades of hydropower plant. Nepalese river are sediment laden type that carries huge mass of sand from upstream to downstream [1]. Most of the hydro power plant built and going to built are of run off river type, being overloaded sediment in Nepalese river has made the hydropower plant more susceptible[1,2]. So sediment is considered as most sensitive element in hydropower plant that determines the efficiency,life and status of hydro mechanical components. Past experience, research and findings has augmented the need of deep study on sediment characterstics and its direct impact on turbine material.

This research is articulated in defining sediment characterstic in turbine material. This effort is done to find out impact of Modi River sediments on turbine material. Modi river is one of the river that flows in western part of Nepal with more than 7 hydroprojects with capacity more than $140 \mathrm{MW}$. This river has total head approximately of 850 meters with approximate design discharge of river $25 \mathrm{~m}^{3} / \mathrm{s}$.

\section{SAMPLING}

Sand particle samples were collected from different major river beds and fluvial contents of Modi River. Sand samples were collected from eight different stations considering tributaries and human interference zone of the river; samples were utilized to find the impact of sediments on test specimen using rotating disc apparatus. To study the impact of sediment on turbine material, sediment size smaller than 200 micrometers were used. Sizes of sediment were characterized using sieve analyzer. Three different tests each with 
30 grams samples were performed for all eight locations to find out more accurate impact value of sediment. Sand samples profile was visualized from profile projector and its impact on test specimen were determined from rotating disc apparatus. Sediment samples were collected from Jhinudada, Siwal, Birethati, Patichaur, Ambot, Dobilla, Majhigaun and Majhbumi site of Modi River. Along this river, tributaries river Dhoti Khola Joins at location 3 (Birethati), Pati Khola and Jare Khola joins at location 6 (Dobilla), Tamadi Khola and Baguwa khola joins at location 7 (Majhigaun), Malyandi Khola, Rugdi Khola and Raineula Khola joins at location 8 (Majhbumi) which is shown in below google map (figure 1) where sediment sample for erosion test were collected. There are seven hydro projects of total 118.1 MW capacities in Modi River, among these seven projects only Modi project has been constructed which has total capacity of $14 \mathrm{MW}$ and is promoted by Nepal Electricity Authority and others are proposed which are listed below (table 1).

\begin{tabular}{|l|l|l|l|}
\hline S. No. & Project Name & $\begin{array}{l}\text { Capacity } \\
\text { (MW) }\end{array}$ & Promoter \\
\hline 1 & Super Modi & 43 & Nepal Electricity Authority \\
\hline 2 & Upper Modi & 14 & Nepal Electricity Authority \\
\hline 3 & Modi Khola & 15.1 & $\begin{array}{l}\text { Himal Hydro and General Construction co. } \\
\text { ltd }\end{array}$ \\
\hline 4 & Modi & 14 & Nepal Electricity Authority (Running) \\
\hline 5 & Lower Modi & 10 & Panchakanya group \\
\hline 6 & $\begin{array}{l}\text { Lower Modi } \\
1\end{array}$ & 10 & $\begin{array}{l}\text { United Modi Hydropower Development } \\
\text { Company Pvt. Ltd. }\end{array}$ \\
\hline 7 & $\begin{array}{l}\text { Lower Modi } \\
2\end{array}$ & 12 & $\begin{array}{l}\text { United Modi Hydropower Development } \\
\text { Company Pvt. Ltd. }\end{array}$ \\
\hline
\end{tabular}

Table 1: Hydro projects in Modi River.

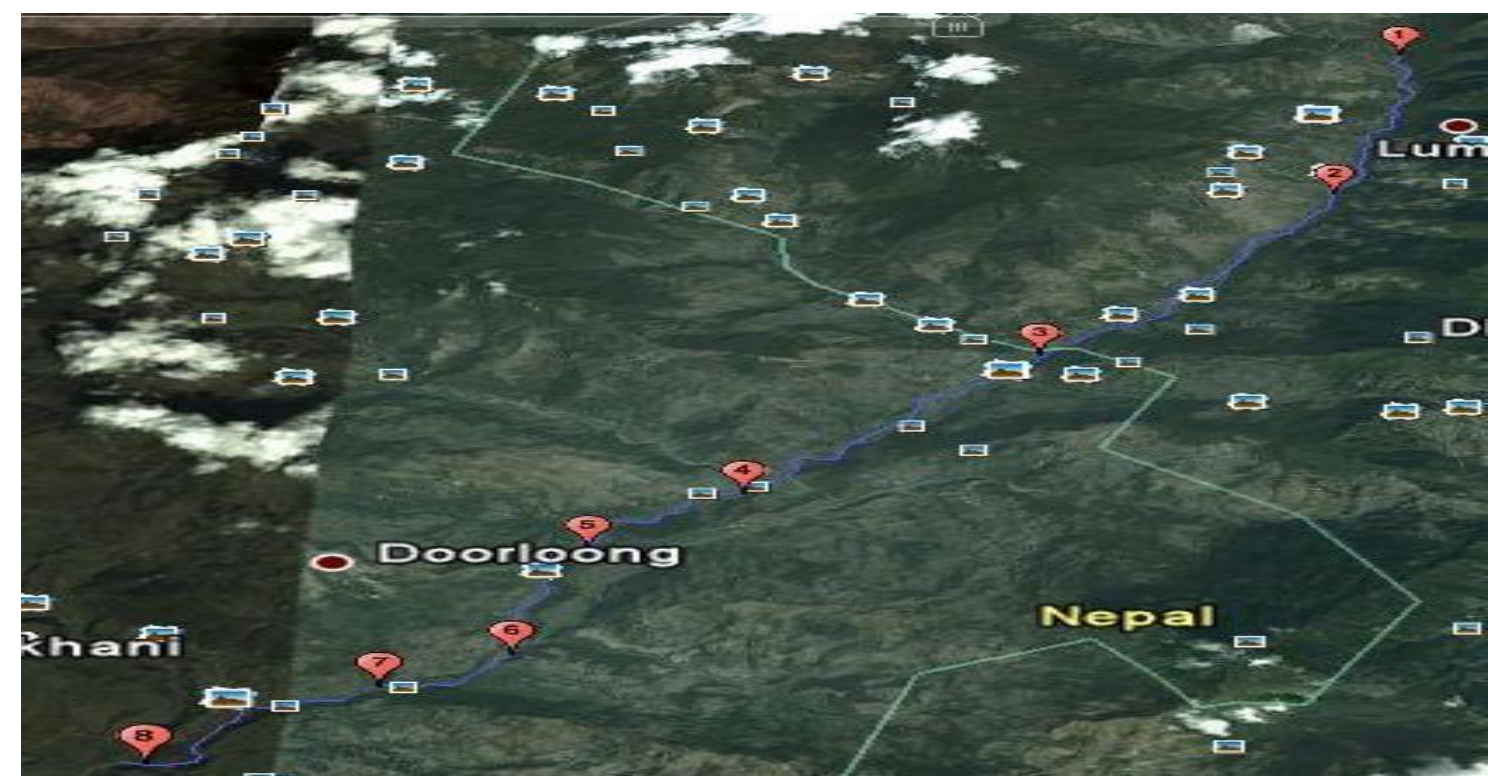

Figure 1: Google Map of 8 stations of Modi River

\section{ROTATING DISC APPARATUS}

Rotating disc apparatus is used to determine the erosion of test specimen by Modi river sand particles. This erosion testing rig consists of motor, nozzle, rotating disc with specimen (figure $2(a, b)$ ). Rotating disc has four evenly polar spaced holes where test 
specimens of same material, weight and type were screwed. These specimens were screwed up tightly in rotating disc plate. Before screwing the test specimens, test specimens were gently dipped in acetone, dried up and weighted using weighing machine. Test specimens were screwed in such a way that the screwed part holds the disc tightly in a same rotating disc plane where as in another part sand samples strike the test specimens and the part is slightly protuberated from the rotating disc plane. The whole apparatus consist of one nozzle just above and parallel to rotating disc that directs towards protuberated test specimen. This disc is attached to whirling shaft of motor, when motor gets started the disc rotates where four test specimens are attached. While being rotated sand samples with water impinges the turbine test specimen through the nozzle. Three liters of water mixed up with 30 grams of sand sample were used to test the specimens and each test is done for five minutes. After 5 minutes, test specimens were taken out from rotating plate, dipped in acetone, dried and weighted to find out the weight loss from its original weight. Consecutively three tests were performed for each location. This method helps to find out erosion on four different specimens with same concentration of sediment which gives more accurate erosion data. All the activities performed in this test are manual and the data were recorded manually.

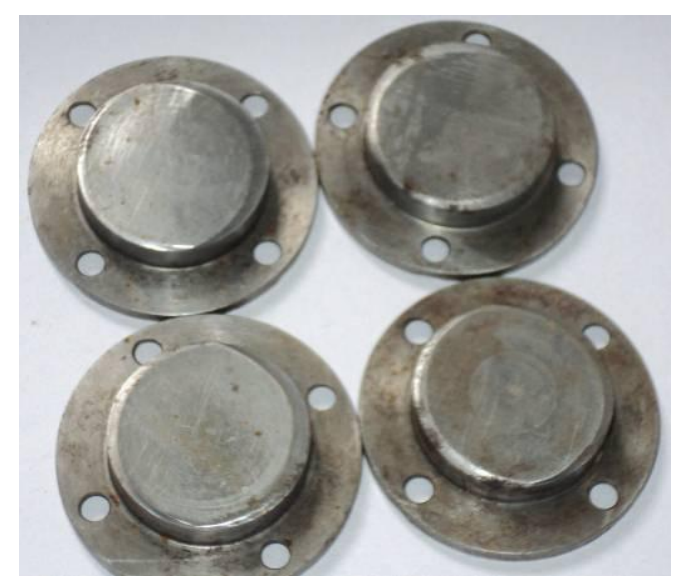

Figure 2a: Test specimen

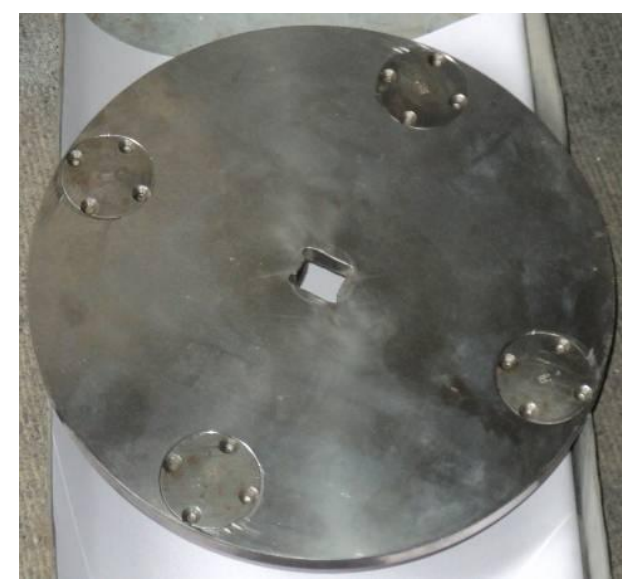

Figure 2b: Rotating disc

\section{MINERAL CONTENT}

Sand particles are substrate of rock and are composite of different minerals. While analyzing mineral content big sizes pebbles and grains were separated from sieve and only sand below 200 micro meters were studied. Mineral content analysis was done using acid wash technique where samples were treated with $10 \%$ dilute hydrochloric acid. Chemical reaction takes place between minerals of sand and acid as a result sediment loses its weight. The weight loss is taken as the carbonate content in the minerals. About $40 \%$ of sample contains Carbonates. Experiment showed that it contains largely Quartz, Feldspar, Mica, Carbonates, Clay, Chlorite and Fragment of Dolomite, Calcite and Shale whereas Tourmaline, Hornblende, Garnet are in small amount. Mineral content of sediment are different in different rivers because of parent rocks in different parts are different from where these sediments has been fragmented. So we can observe difference in mineral content of Roshi and Modi rivers. 


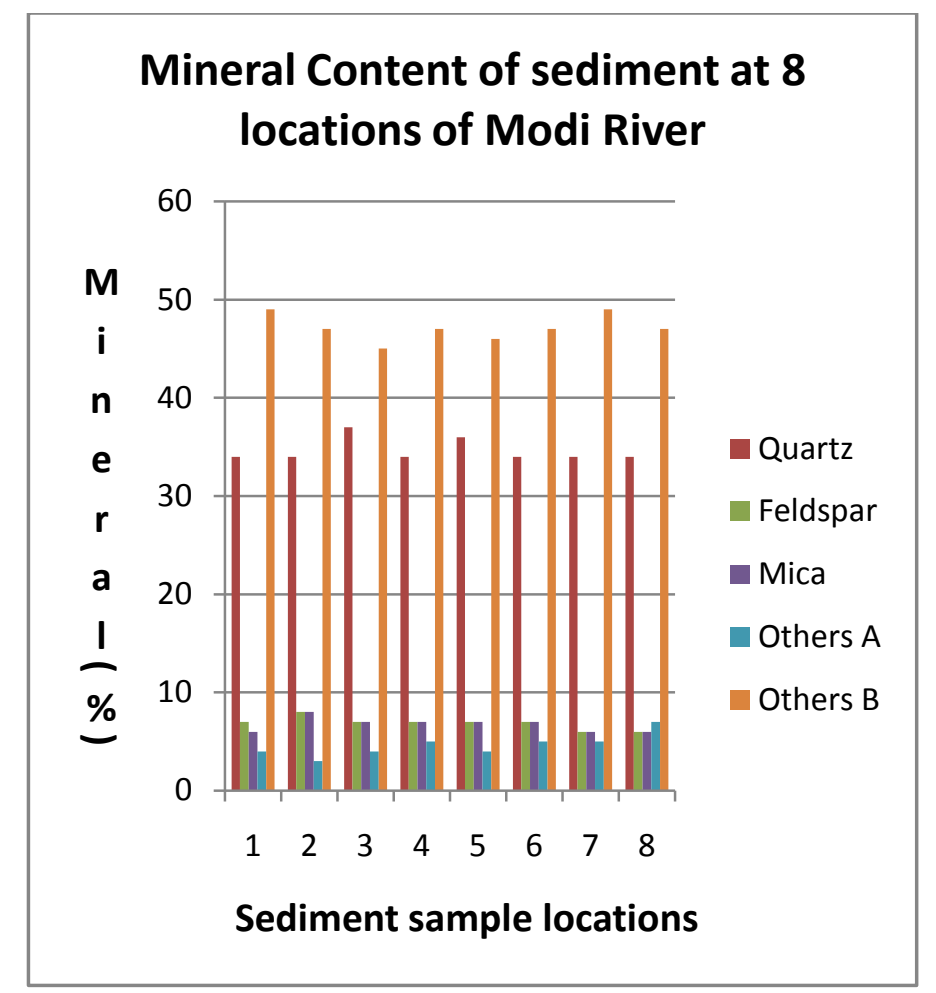

Figure 3: Mineral content on sediment samples of Modi River

Modi River sediment particles are rich in minerals, among different mineral content quartz is found in high percentage followed by Feldspar and Mica. Quartz content varied from 34 to 37 percent, Feldspar 6 to 8 percent, Mica 6 to 8 percent, other A 3 to 7 and B content 45 to 49 percent in all eight locations of the river section. These are the three dominating mineral content whereas others $\mathrm{A}$ is the least minerals found in the sample that represents tourmaline, Hornblende and Garnet while as others B represents more mineral than all other content it includes Carbonates, Clay, Chlorite and Fragment of Dolomite, Calcite and Shale.

\section{RESULTS AND DISCUSSION}

Impact on turbine material test specimen by sediment of Modi River were analyzed in two different ways, firstly impact on four turbine material specimen of same type, weight and material by same sand sample and another impact on four turbine material by different three sand samples of eight different locations of Modi River. Impact on turbine material is defined in terms of weight loss in this study. It is very cumbersome to discuss and define each impact value on chart, so to make the analyzing process easier all impact values of four different materials are shown in same bar chart. Below charts 4, 5, 6 and 7 shows results of the experiment. The horizontal axis shows the sand sampled locations of Modi River whereas the vertical axis shows the impact on turbine material by sediment in the basis of weight loss in mgs. The bar chart shows four different color bars indicating the turbine material which is of same type, weight and material. These all four turbine specimens attached in single rotating disc apparatus impact variation were observed and analyzed by summing up to give the average impact value on this turbine material specimen by sediment of Modi River. 


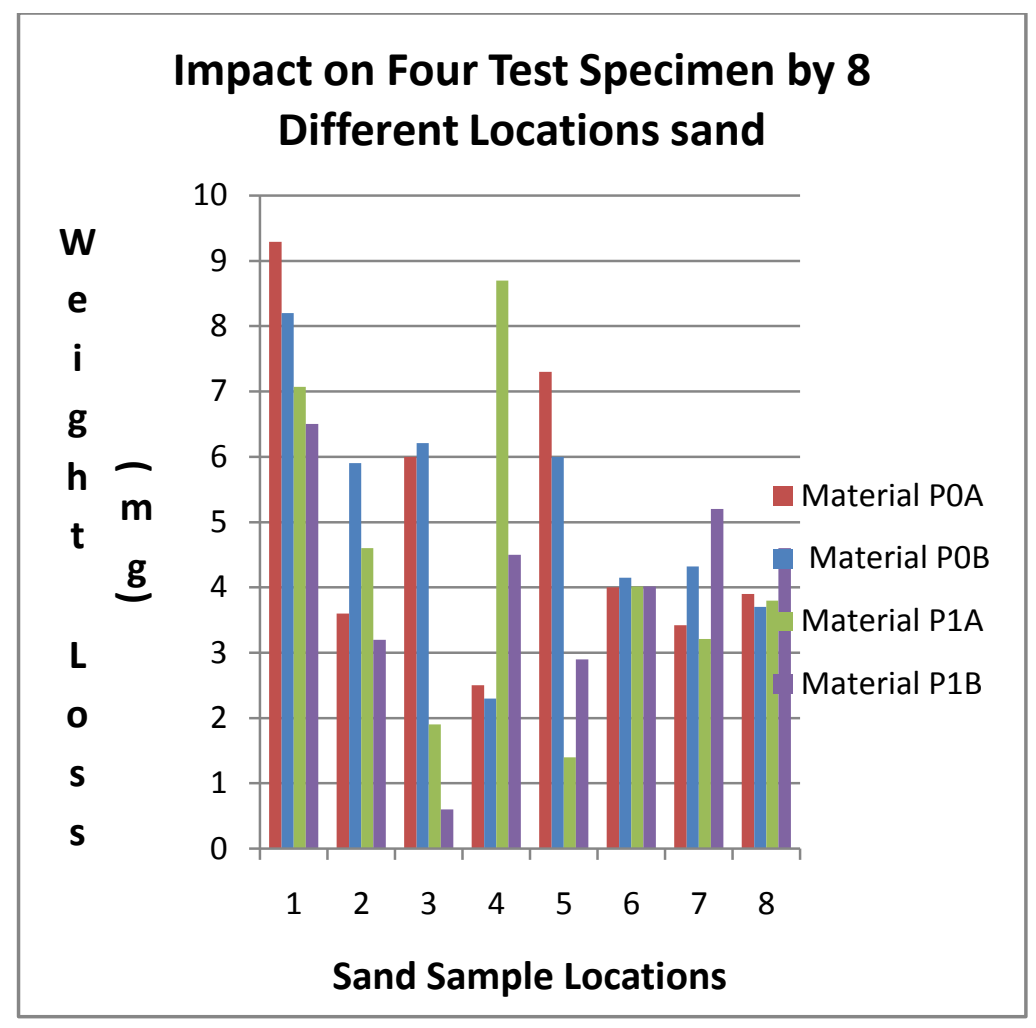

Figure 4: Impact on Four Test Material at 8 different locations sand

Above (figure 4) shows a distinct impact of four turbine specimens with same sand samplesof eight different sections of the river. It is observed that impact values on specimens by sediment of location number 1 is comparatively higher than other locations. It is also found that impact values on specimens by sediments of locations 2, 3, 4 and 5 have high fluctuation but afterwards moving towards downstream sediment, the values of impact are in same range. The impact values of sediment at locations 6, 7 and 8 are less, so it can be predicted that the sediments in upstream are more harse in nature that helps in fast degradation of turbine material rather than the sediments of downwards. It is found that the highest impact value is $9.289 \mathrm{mg}$ which is the weight loss of turbine material P0A by the sediment of location 1. It is found that the least effect is done by sand sample of location number 3 with a value of 6 on material P1B. P0A test specimen has been least damaged by sand sample of location number 4 and than by 7 . Test specimen P0B has been greatly damaged by sediment of location number 1 with a weight loss value of 8.2 $\mathrm{mg}$ and least damaged by sediment of location number 4 with a value of $2.3 \mathrm{mg}$. The green bar standing showing the impact of test material P1A is highly worn out by sand samples of location 1 with $7.07 \mathrm{mg}$ loss of weight and least affected by sand sample of location 5 with a loss of $1.4 \mathrm{mg}$. The fourth specimen P1B has also been highly damaged by sediment of location 1 and least damaged by sediment of location number 5 . Location number one sediment have high impact values in four different specimens. It may be due to nature of sediment transportation in this spot and highly tributaries junction point with high human interference zone. 


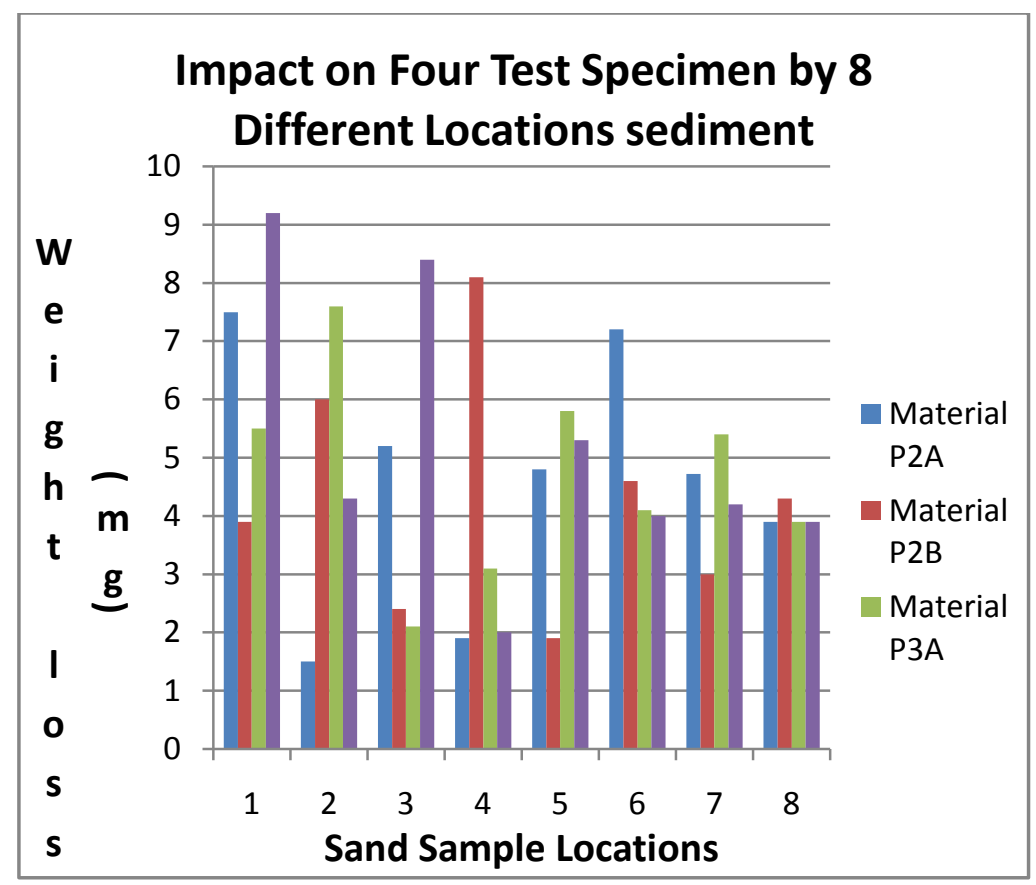

Figure 5: Impact on Four Test Material by 8 locations sediments

Figure 5 shows the same characterstic chart like above, where different another four material is utilized. Same kind of analysis is done to find out the average impact value range on test material and sediment characterstic of Modi River. Here in this chart we can found a little difference than above chart. The range of impact in this chart is slightly lower than above one with highest impact value of $9.2 \mathrm{mg}$ on specimen P3B by sediment of location 1 and least impact $1.5 \mathrm{mg}$ on material P2B by sediment of location 2 . In this chart also we can see fluctuation of values greatly in all locations sediment but it can also be drawn out that the impact range in downstream of the river is more or less equal.

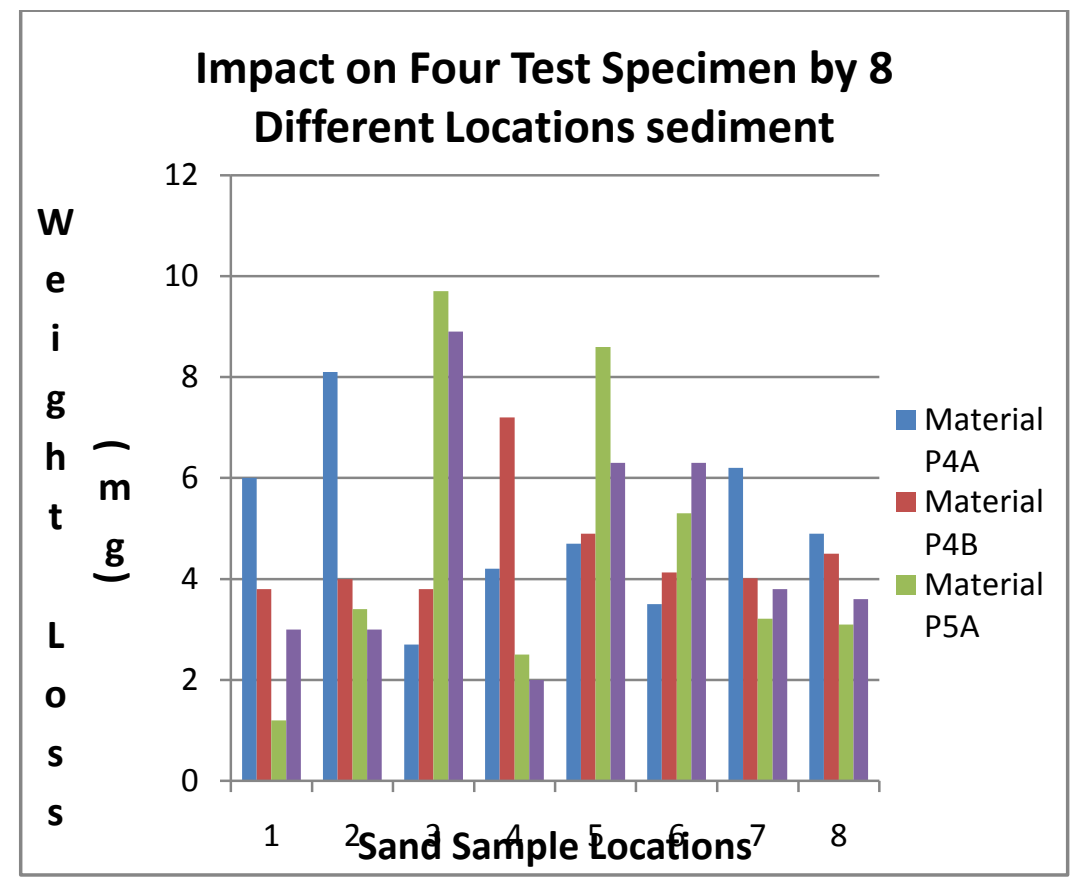

Figure 6: Impact on Four Test Material by 8 locations sediments 
This figure 6 also represents the same like above chart, in this chart sand sample of location 3 have more damaging properties than other bars with highest value of $2.7 \mathrm{mgs}$ on material P5A and have least value $2 \mathrm{mg}$ on material P5B by sediment of location 4. It is depicted from the chart that the sediment of location no 7 have somewhat equal eroding value.

This chart shows the final averaged sediment impact on test material of Modi river. It shows that the impact or loss of weight of test specimen can extend from 4.008 to 7.517 $\mathrm{mg}$. The erosion rate lies within this range.

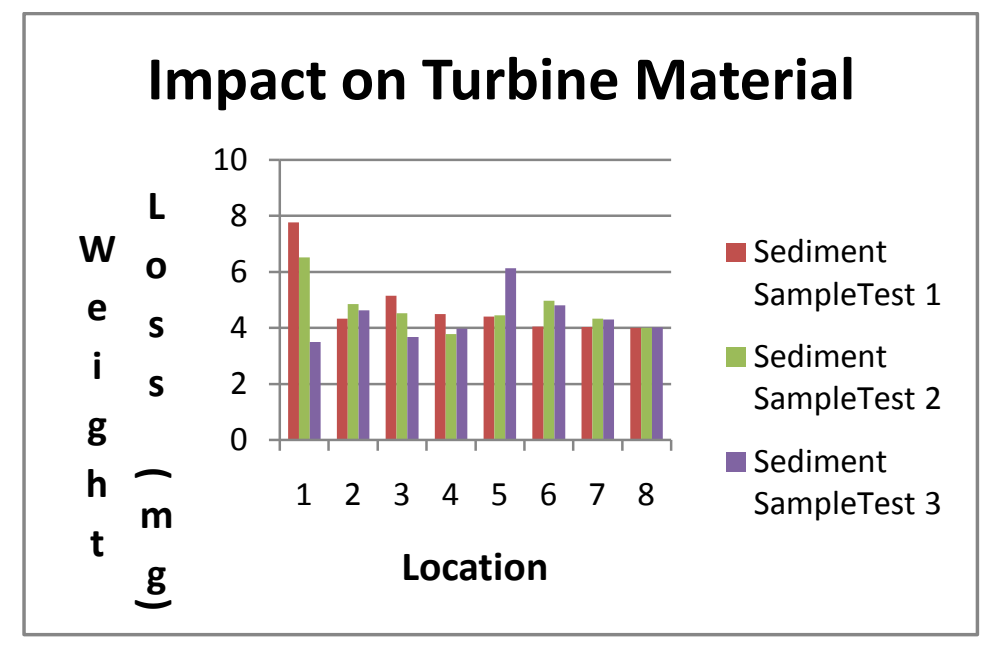

Figure 7: Impact on test material by 3 different samples from each location

The above bar chart (figure 7) depicts the true erosion on turbine material by three different sand samples collected from each location. It is found that sand sample i.e. test one has great impact on turbine material with material loss of $7.76475 \mathrm{mg}$ whereas test 3 sample has least impact value at same first location with $3.5 \mathrm{mg}$ weight loss. It is observed that sediment of sample test 1 have highest and sample 3 have least eroding effect by sediment of location no 1 and also have high difference of impact value than other locations impact.

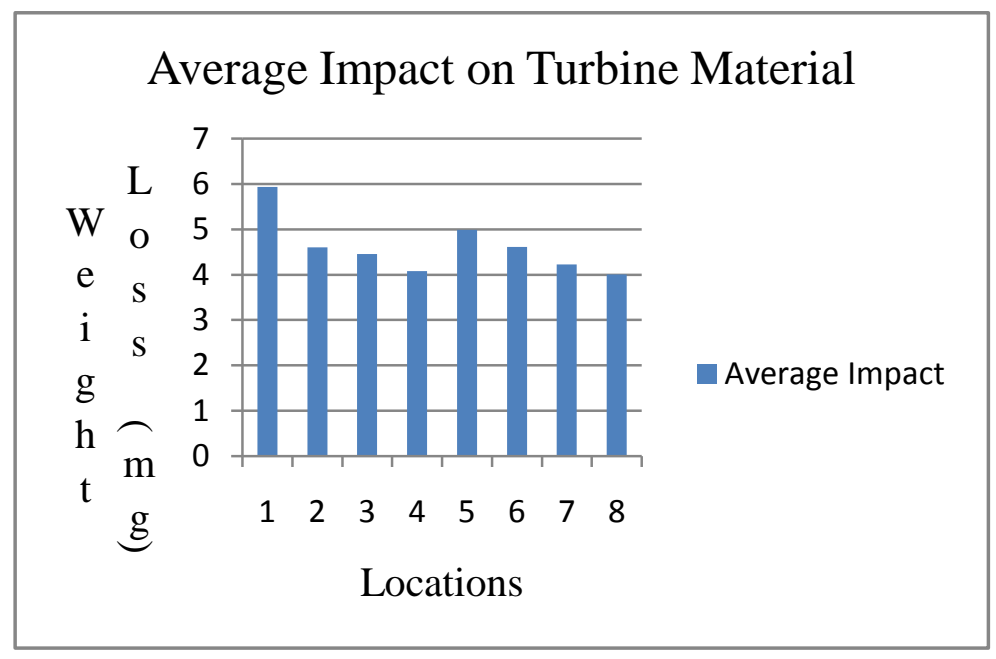

Figure 8: Average Impact on test turbine material 
Figure 8 shows the average impact value of sediment of Modi River on the surface of turbine specimen. This bar chart is average of all turbine specimens' impact value in each individual location. It is observed that the location 1 sediment have high eroding nature with impact value of $5.929 \mathrm{mg}$ and location 8 sediment have least eroding value of $4.00833 \mathrm{mg}$. It can be seen from the chart that the average impact values in all locations are within the certain range and have low fluctuation.

It is observed that the eroding nature of sediments from upstream to downstream have more or less similar kind of eroding pattern by three different sand samples on test material. So it can be assumed that this test specimen material has above pattern of eroding effect by sand particles of Modi River. It is clearly depicted from the above result that the sediment at downstream are less eroding than the sediments from upper part of the river. From this result we can clearly accept that the more the sand particles roll from upper section of the river less will be the eroding nature.

\section{CONCLUSION}

Turbine is one of the important parts of hydropower, it plays vital role in its efficiency which directly has impact on plant efficiency and turn to electricity production and life of power plant. It is worthy to study sediment of river where power plant is going to build it gives clear picture on selection of settling basin, hydro mechanical equipments and turbine material. The eroding nature of sand depends upon the size, shape, mineral content of sediment and flowing properties of water. This paper examines the nature of sediment impact of Modi River on turbine specimen using rotating disc. The result from above experiment has shown that the first location sediment have high eroding property from both kind of test. It has high impact value with weight loss of $7.764 \mathrm{mg}$ on first rotating disc with sand sample of location 1 and least $3.5 \mathrm{mg}$ on third rotating disc by same location sediment but by sand sample 3.The average impact is highest by sediment of location 1 with weight loss of $5.929 \mathrm{mg}$ and least by sand samples of location 8 with weight loss of $4.008 \mathrm{mg}$. It is evident from the above result that the sediment particles of Modi River have more or less same eroding properties at upstream and downstream. According to above result it is concluded that the sediments in course of rolling down from upstream to downstream its shape and size changes and have less eroding property than one found in upstream of the river.

\section{REFERENCES}

[1] Thapa B, Sand Erosion in Hydraulic Machinery, Ph. D. Thesis, NTNU 2004:105.

[2] Thapa B, Shrestha R \& Dhakal P, Sediment in Nepalese hydropower projects, Proc, Int. Conf. on the great Himalayas: climate, health, ecology, management and conservation, Kathmandu, 2004.

[3] B P Shrestha, B Gautam \& T R Bajracharya, Computational analysis of Pelton bucket tip erosion using digital image processing, Proc. SPIE 6833, 781-948, China, 2007.

[4] B P Shrestha, N K Shrestha \& L Poudel, "Classification of Biological and Non Biological Fluvial Particles Using Image Processing and Neural Network," 734321, accepted and presented in International Conference of Society of Photonics and Instrumentation Engineers, Orlando, Florida, USA, April 13-17, 2009. 
[5] J Blott \& K Pye, Particle shape: "a review and new methods of characterization and classification”. Sedimentology 55 (2008) 31.

[6] B P Shrestha, S K Suman \& P Manandhar, "Fluvial-sedimentary Solid Characterization using Broadband Imaging and Artificial Neural Network," International Conference on "For a better tomorrow - Sustainable Solid Waste Management In Developing Countries”, Jan $11^{\text {th }} 2006$, Kathmandu, Nepal.

[7] B P Shrestha, B Gautam \& M Nagata, "Fluvial Particle Characterization using artificial neural network and spectral image processing" Society of Photo-Optical Engineers, 6833(2007)304.

[8] T R, Bajracharya, D Sapkota, R Thapa, S Poudel, C B, Joshi, R P Saini \& O G Dahlhaug, "Correlation Study on Sand Led Erosion of Buckets and Efficiency Losses in High Head Power Plants", Proceedings of First National Conference on Renewable Energy Technology for Rural Development, Kathmandu, Nepal,1214th October 2006. 